\title{
Estudiar las transformaciones contemporáneas del trabajo desde una perspectiva psicosocial
} Studying the contemporary transformations of work from a psychosocial perspective

\author{
Vicente Sisto \\ Pontificia Universidad Católica de Valparaíso \\ Carla Fardella \\ Universidad Nacional Andrés Bello
}

\section{Resumen}

La investigación social ha mostrado que las transformaciones del trabajo se vinculan con los procesos de construcción de subjetividad y de vinculo social. Estas transformaciones se despliegan de modos heterogéneos e incluyen discursos que justifican, regulaciones, instrumentos y materialidades que las estructuran y sostienen, así como subjetividades y prácticas. Este artículo presenta una aproximación psicosocial para el estudio de las transformaciones contemporáneas del trabajo. Para ello presentamos algunos lineamientos acerca de qué debe ser considerado como parte del campo de análisis y cómo esto puede ser realizado, ilustrándolo con los artículos que forman parte de este número.

Palabras clave: Trabajo; Transformaciones sociales; Subjetividad; Psicología social

\begin{abstract}
Social research has shown that the transformations of work are linked to the processes of construction of subjectivity and social bond. These transformations unfold in heterogeneous ways and include discourses that justify, regulations, instruments and materialities that structure and sustain them, as well as subjectivities and practices. This article presents a psychosocial approach to the study of contemporary work transformations. For this, we present some guidelines about what should be considered as part of the field of analysis and how this can be done, illustrating it with the articles that are part of this issue.
\end{abstract}

Keywords: Work; Social transformations; Subjectivity; Social psychology 


\section{INTRODUCCIÓN}

El trabajo ha sido señalado insistentemente como uno de los principales mecanismos de articulación social. Es a través del trabajo que el sujeto vincula su actividad en el proceso de producción social, a cambio de lo cual recibe no solo una remuneración, sino que también un "lugar" social, teniendo un papel fundamental en la conformación de las subjetividades y en los procesos de construcción societal (ver Bauman, 2000; Gorz, 1991; Kuhn, 2006; McCabe, 2007; Moore y Robinson, 2015; Sennett, 2000; Strangleman, 2005). Considerando esta centralidad otorgada por la teoría social, durante las últimas décadas ha emergido una creciente preocupación por las transformaciones del trabajo, en un contexto caracterizado por crisis estructurales de las sociedades capitalistas y procesos de reestructuración productiva que estarían transformando radicalmente la naturaleza del trabajo, al menos tal como se había pensado en el contexto de las sociedades salariales (Antunes, 2014; Beynon, 2015). Este proceso interpelaría no sólo las identidades sociales de los sujetos, sino que también las formas de sociabilidad (Bauman, 2007; de la Garza, 2016). Individualización, fragmentación social, liquidificación de nuestras sociedades, han sido algunas de las caracterizaciones y descripciones que se han dado a estos procesos de transformación social vinculados a los cambios en el trabajo (Bauman, 2007; Beck, 2003; Binkley, 2009; Meda, 1998; Rose, 1996; Sennett, 2000).

Lo anterior demanda una comprensión del trabajo capaz de abordar esta complejidad social, subjetiva, regulatoria y material, que estaría caracterizando estos procesos de transformación. He ahí el lugar y relevancia de una perspectiva psicosocial que aborde las transformaciones del trabajo contemporáneo. Este número, a través de los artículos de la sección Estudios psicosociales de las transformaciones contemporáneas del trabajo, busca contribuir en la comprensión del devenir contemporáneo del trabajo desde investigaciones situadas en distintos ámbitos laborales, desarrollando análisis orientados a dar cuenta ese complejo entramado relacional que constituye este devenir.

A través de estas líneas introductorias esperamos mostrar ciertas pistas acerca de qué puede ser un abordaje psicosocial de las transformaciones contemporáneas del trabajo. Para ello, presentamos algunos lineamientos acerca de qué debe ser considerado como parte del campo de análisis y cómo esto puede ser realizado, presentando los artículos que componen la sección. 


\section{EL TRABAJO Y SUS TRANSFORMACIONES COMO CAMPO DE INDAGACIÓN PSICOSOCIAL}

El trabajo no es una mera ejecución por parte de una persona o grupo, de prescripciones derivadas de diseños de puesto, arquitecturas gerenciales, o regulaciones legislativas. El trabajo es ante todo un despliegue práctico de carácter sociomaterial, en el cual las prescripciones y regulaciones que buscan organizar y estructurar la acción son siempre actuadas conjuntamente por sus actores humanos (las, los trabajadores) y no humanos (herramientas, máquinas, protocolos, mobiliarios y otros).

En este espacio de relación participan interpelaciones acerca de qué es el trabajo, cuáles son las actividades que supone, cómo debe hacerse y cómo es quien debe realizarlo. Estas provienen de discursos gerenciales o institucionales, pero también desde otros lugares de enunciación con fuerza estructurante: grupos de interés, asociaciones empresariales, think tanks y otros, interpelando a través de medios de comunicación (columnas de opinión, editoriales, presencia en medios audiovisuales, etc.), buscando estructurar un campo de legitimación acerca de cómo debe ser el trabajo, cómo debe ser regulado, ejecutado y quienes y cómo deben ser las y los trabajadores. Esto se ilustra en la discursividad que prolifera en los medios en los contextos de reforma, como ha ocurrido en los últimos años en torno al trabajo de repartidores, profesores, trabajadores del ámbito de salud, académicos, y otros. A éstas, se suman otras interpelaciones que provienen de tradiciones de oficio y/o profesionales, referentes vocacionales, comprensiones culturales y otras desarrolladas situadamente por grupos sociales, que contienen definiciones acerca de lo que es y debe ser "el trabajo" en tanto actividad social remunerada realizada en la esfera pública, y en tanto "trabajos", considerando la multiplicidad de actividades laborales; e incluyen comprensiones acerca de quienes son las y los sujetos del trabajo, promoviendo cuál es su lugar en lo social, cuáles son sus características, derechos, deberes y responsabilidades. Estas interpelaciones trazan discursivamente el espacio del trabajo, constituyendo un campo argumentativo sobre el cual se sustentan regulaciones, prácticas organizativas, instrumentos de gestión, así como las prácticas situadas de los diversos actores posicionados en los diferentes niveles mediante los cuales se despliega el trabajo.

Ese despliegue práctico ocurre, por lo tanto, en un espacio trazado discursivamente por múltiples y heterogéneas interpelaciones, pero realizado a través de las acciones concretas de actores humanos y no humanos conectados en la actividad conjunta. Descripciones de cargo, reglamentaciones y otras regulaciones organizacionales, instrumentos, registros, herramientas, maquinarias, configuraciones arquitectónicas, trabajadoras y trabajadores es ubicados en distintos 
niveles y categorías organizacionales, todos participan del despliegue práctico sociomaterial que constituye al trabajo como realización activa. Ahí emergen nuevas configuraciones que incluyen prácticas de resistencia y transformación de lo prescrito, así como diversas formas de organización colectiva.

Es en este campo donde se juega el potencial productivo del trabajo, en cuanto actividad que produce sociedad y produce subjetividad.

\section{ESTUDIAR EL TRABAJO DESDE UNA PERSPECTIVA PSICOSOCIAL}

La anterior comprensión del trabajo y sus transformaciones como campo de indagación nos orienta a análisis que consideren las interpelaciones que son realizadas desde diversas posiciones buscando estructurar el trabajo. Dos artículos de este número especial muestran ejemplos de este tipo de análisis

Vicente Sisto, Lorena Núñez-Parra y Guillermo Rivera-Aguilera, en el artículo Entre managerialismo y nostalgia. El debate por el futuro de la Universidad y el Trabajo Académico, muestran cómo, en un contexto de reforma de las políticas de educación superior en Chile, mediante los principales medios de comunicación escritos, se despliega una disputa en torno a qué es el trabajo académico, quiénes son sus trabajadores y cómo debe ser organizado, promoviendo managerialismo, por un lado, instando a políticas de rendición de cuentas basada en resultados, a lo cual se opone un discurso de tipo nostálgico, según denominan los autores. Este contrapone al discurso managerial, imágenes de lo que sería un pasado añorado de lo que fue el trabajo académico. Así diversas interpelaciones disputan qué es el trabajo académico.

El texto de Magdalena Garcés Ojeda, Pamela Frías Castro y Antonio Stecher Sentidos del trabajo en el capitalismo de plataformas: Análisis de narrativas audiovisuales en la gig economy, dan cuenta de cómo, mediante producciones audiovisuales de tipo publicitario, empresas de capitalismo de plataformas promueven ciertos sentidos del ser trabajador de este tipo de empresas, mediante imágenes que construyen al trabajador, a la empresa y a la actividad misma de trabajar en este tipo de empresas, mediante categorías tales como autonomía, flexibilidad, dinamismo, alto desempeño y utilidad social. Con ello, legitiman estas formas de trabajo, naturalizando e invisibilizando los mecanismos de precarización y dominación social, interpelando no sólo a las y los trabajadores, sino que también a la sociedad en su conjunto legitimando ciertas formas de trabajo.

El estudio de los discursos que interpelan legitimando debe ser complementado con el abordaje de los instrumentos específicos que regulan el campo práctico que concreta el trabajo. El artículo Objetos proposicionales: una política orga- 
nizacional mediada por documentos de Jorge Castillo-Sepúlveda, Mariana Gálvez-Ramírez y Fernanda Bywaters-Collado, a partir de un estudio en el campo de la medicina, analiza las acciones que prescribe y promueven las guías de práctica clínica. Recogiendo la influencia de la filosofía procesual de Whitehead, muestran cómo estas guías, en tanto objetos proposicionales, se posicionan estructurando un campo de acción, concretando las potencialidades normativas del escenario en el cual actúan. Pero esto lo hacen en tanto actuando en un espacio heterogéno, conectando su acción a la de otros agentes. Así, estos instrumentos regulatorios se sitúan planteando relaciones, afectando a otros agentes, a la vez que siendo modulados, afectados actuando en lo que denominar "arreglos situacionales pragmáticos". Así, la fuerza regulatoria de la guía clínica como instrumento es modulada en un campo de acción en el cual ésta se sitúa desde la conexión abriendo nuevas proposiciones, nuevas posibilidades.

Las interpelaciones sociales que buscan modelar los campos específicos de trabajo, así como las regulaciones e instrumentos que actúan con fuerza estructurante sobre la actividad conjunta, promueven directa o indirectamente determinadas identidades laborales afines al orden que se busca promover. Estas identidades se despliegan heterogéneamente, adscribiendo o distanciándose de los modelos de ser y hacer promovidos. El estudio de identidades laborales en un contexto de interpelaciones discursivas y desempeño de instrumentos de gestión ha ocupado un lugar importante en la investigación acerca de los efectos sociales y subjetivos de las transformaciones del trabajo. Este número incluye dos artículos claramente orientados a este tipo de estudio, ambos vinculados al campo del trabajo académico.

El primero está escrito por Carla Fardella Cisternas, Javiera Garcia-Meneses, Álvaro Soto Roy y Alejandra Corvalán-Navia, y se titula Exacerbados. Identidades académicas y la transformación de la educación superior chilena. Éste aborda cómo los modelos e instrumentos de gestión instalados en el campo universitario han promovido ciertos modelos de identidad laboral vinculados a la productividad y emprendimiento individual como símbolos de prestigio, estos modelos han sido impulsados por políticas de financiamiento, evaluación e incentivos. Sin embargo, estos modelos no son asumidos por las y los académicos de modo llano. Mediante el análisis de entrevista las y los autores muestran la emergencia de diversas narrativas identitarias, algunas con mayor proximidad a los modelos promovidos, pero otras que se distancian, mostrando heterogeneidades y la emergencia de nuevas posiciones subjetivas ante estas interpelaciones y regulaciones. 
Por su parte, el artículo Resistencias y reproducciones de mujeres académicas: Estrategias de supervivencia en la academia patriarcal/neoliberal, de Giazú Enciso Domínguez, Maite González Yañez y Francesca Chiappini ,aborda cómo las mujeres científicas desarrollan estrategias para habitar y actuar en un espacio creado y estructurado por y para hombres, bajo modelos patriarcales de organización del trabajo que conectan con las improntas manageriales que dominan las actuales políticas de gestión universitarias y de trabajo académico. Mediante el análisis de entrevistas, las autoras muestran cómo las científicas, en sus narrativas, dan cuenta de resistencias estos modos de organizar el trabajo, pero a la vez dichas resistencias están plenas de estrategias que tienen como efecto la reproducción de los mismos sistemas de los que desean rebelarse. Reproducción, resistencia y transformación expresándose, juntos, conectándose de modos heterogéneos en las narrativas de quienes habitan el ser científicas bajo una organización generizada y managerializada del trabajo académico.

Tal como se aprecia, la investigación en torno a narrativas identitarias tiende a mostrar cómo los discursos y las regulaciones e instrumentos que actúan estructurando el espacio del trabajo interpelan a las subjetividades laborales, las cuales adscriben de modos híbridos a dichas interpelaciones. Sin embargo, emergen distancias, fisuras, que fracturan estas prescripciones, mostrando que el campo de la inscripción subjetiva es mucho más heterogéneo, dificultando el moldeamiento de las subjetividades en función de lo promovido. Estas heterogeneidades se hacen claras y explícitas también en el abordaje etnográfico de las practicas conjuntas mediante las cuales se despliega el trabajo como una realización material y simbólica.

En efecto, los estudios empíricos en trabajo paulatinamente han ido girando, desde el foco en las subjetividades como identidades laborales, hacia el estudio de la práctica y vida cotidiana como espacio de fisura y transformación. Así la investigación empírica en espacios laborales que ha adoptado enfoques de carácter más etnográfico ha logrado dar cuenta, de un modo aún incipiente, de cómo en espacios tan fuertemente estructurados por instrumentos de gestión y formas contractuales profundamente individualizantes y que fomentan la competencia, emergen prácticas que subvierten este orden. Éstas no son reportadas fácilmente en entrevistas o encuestas. Sin embargo, la aproximación etnográfica en distintos contextos laborales ha mostrado que este tipo de prácticas existen y trascienden a una mera resistencia de oposición (Fardella y CarvajalMuñoz, 2018; Sisto, 2019). A través de estas acciones se asoman formas de acción y de vinculación social de carácter solidario y cooperativo, que buscan preservar lo común a pesar de la individualización de la organización del trabajo prescrita. 
He ahí que toma centralidad la noción de práctica para un abordaje psicosocial que penetre en el entramado de relaciones que constituye el despliegue del trabajo y sus procesos de transformación (Fardella y Carvajal-Muñoz, 2018; Gherardi, 2009; Keevers et al., 2012; Sisto, 2019; Sisto y Zelaya, 2014).

Cuatro trabajos de esta sección, si bien no necesariamente adscriben explícitamente al enfoque centrado en prácticas, desarrollan un tipo de investigación de carácter etnográfico que busca penetrar en estos entramados materiales y semióticos mediante los cuales se despliega el trabajo como realización situada.

El texto de Karol Morales Muñoz, denominado Etnografía psicosocial de colectivos laborales emergentes en modalidades de vinculación flexible: Una propuesta teórico-metodológica, desde el estudio de diversas modalidades de vinculación laboral caracterizadas por la falta de protección y su distancia con los modelos de relación salarial, presenta una "etnografía psicosocial de colectivos laborales", la cual articula enfoque tales como el estudio del cotidiano, la investigación en torno a prácticas desde la mirada organizacional y la centralidad del discurso en las disputas laborales contemporáneas.

También, desde un enfoque centrado en prácticas, esta vez bajo la influencia de la teoría del actor red, el artículo El trabajo de la judicatura laboral: directrices legales, colaboración y afectos de Iván Grudechut penetra en el trabajo de los jueces de los tribunales de justicia laboral en Chile. Ahí se muestra cómo, mediante una serie de acciones sostenidas por diversos agentes se despliega una red que orienta a los actores a procesos conciliatorios que pueden incluso distanciarse de los objetivos de lograr una justicia laboral. El artículo muestra con claridad la red de actores humanos y no humanos que incluyen, entre otros, a la afectividad de los cuerpos como actantes en este despliegue conjunto.

El estudio de los trabajadores de las políticas sociales de protección a niños, niñas y adolescentes, el escrito Tensiones y adecuaciones de los trabajadores en el marco de la ejecución de la política social chilena de Javiera Beatriz Pavez-Mena, por su parte, muestra cómo, en un contexto de alta precarización laboral y tercerización y desregulación de las políticas de protección, las y los trabajadores actúan resignación, conjugándolo con una vivencia de temporalidades disímiles. A través de entrevistas y observaciones participantes la autora muestra cómo esto favorece determinadas construcciones de sujeto, que sostienen finalmente la acción pública, en un contexto de alta precarización, mostrando las tensiones de ello. 
Finalmente, la sección se cierra con el texto denominado Resistências ao trabalho precário por meio de relações solidárias: quatro casos do Brasil, de Leny Sato, Egeu Gómez Esteves, Cris Fernández Andrada y Juliana da Silva Nóbrega. Este artículo muestra cómo -en un contexto de "precariedad antigua" solidificada en las relaciones laborales brasileñas, potenciadas por las nuevas formas de vinculación flexible - se desarrollan experiencias de resistencia que son capaces de construir otras relaciones más allá y contra de lo prescrito por los modelos de vínculo laboral individualizantes y precarizantes. Mediante trabajos etnográficos guiados desde la Psicología Social del Trabajo, las y los autores dan cuenta cómo especialmente sectores pobres de la población construyen relaciones de trabajo y de vida social caracterizadas por "la cooperación, la ayuda mutua y vínculos comunitarios", mostrando las posibilidades sostener otras economías y otros modos de sociabilidad más allá de lo prescrito.

Este último trabajo también permite ilustrar cómo el abordaje psicosocial del trabajo y sus transformaciones permite atender a las heterogeneidades que se despliegan de modos situados, permitiendo atender a otras voces y otros modos de hacer las cosas que emergen desde los intersticios de un espacio que, desde miradas más superficiales, podría parecer claramente ordenado y estructurado prescribiendo individualización y debilitamiento de los lazos sociales. En los intersticios de la vida misma del trabajo se construyen otras prácticas, otras relaciones, a las cuales, como investigadores debemos atender. Pues es ahí que se tejen otras subjetividades y otros modos de construcción de lo social.

\section{REFERENCIAS}

Antunes, Ricardo (2014). A nova morfologia do trabalho e as formas diferenciadas da reestruturação produtiva no Brasil dos anos 1990. Sociologia, 27, 11-25.

Bauman, Zigmunt (2000). Trabajo, consumismo y nuevos pobres. Gedisa.

Bauman, Zigmunt (2007). Liquid times: Living in an age of uncertainty. Polity.

Beck, Uirich, (2003), La individualización. Paidós

Beynon, Huw (2015). Beyond Fordism. In Stephen Edgell; Heidi Gottfried \& Edward Granter (Eds.), The SAGE Handbook of the Sociology of Work and Employment (pp. 306-328). Sage. http://dx.doi.org/10.4135/9781473915206.n17

Binkley, Samuel (2009). The work of neoliberal governmentality: Temporality and ethical substance in the tale of two dads. Foucault Studies, 6, 60-78. https: / / doi.org/papers2: / / publication/uuid/AA79CF6A-FE31-44A9-81CF6115682B8A89

De la Garza, Enrique (2016). Los estudios laborales en América Latina: orígenes, desarrollo y perspectivas. Anthropos. 
Fardella, Carla, \& Carvajal-Muñoz, Francisca (2018). Los estudios sociales de la práctica y la práctica como unidad de estudio. Psicoperspectivas. Individuo y Sociedad, 17(1), 12. https://doi.org/ 10.5027/psicoperspectivas-Vol17-Issue1-fulltext-1241

Gherardi, Silvia (2009). From organizational learning to practice- based knowing. Human Relations, 54(1), 131-139. https://doi.org/10.1177/0018726701541016

Gorz, André (1991). Metamorfosis del trabajo. Búsqueda de sentido. Crítica de la razón económica. Sistema.

Keevers, Lyne; Treleaven, Lesley; Sykes, Cristopher \& Darcy, Michael (2012). Made to measure: Taming practices with results-based accountability. Organization Studies, 33(1), 97-120. https://doi.org/10.1177/0170840611430597

Kuhn, Timothy (2006). A “Demented Work Ethic" and a "Lifestyle Firm”: Discourse, Identity, and Workplace Time Commitments. Organization Studies, 27(9), 1339-1358. https://doi.org/10.1177/0170840606067249

McCabe, Darren (2007). Individualization at Work?: Subjectivity, Teamworking and Anti-Unionism. Organization, 14, 243-266. https://doi.org/10.1177/1350508407074227

Medá, Domenique, (1999). El Trabajo: un Valor en Peligro de Extinción. Gedisa.

Moore, Phoebe \& Robinson, Adrew (2015). The Quantified Self: What counts in the neoliberal workplace. New Media \& Society, 18(11), 1-14.

https://doi.org/10.1177/1461444815604328

Rose, Nikolas (1996). Inventing our Selves: Pyschology, Power and Personhood. Cambridge University Press.

Sennett, Richard (2000). La corrosión del carácter. Las consecuencias personales del trabajo en el nuevo capitalismo. Anagrama.

Sisto, Vicente (2019). Managerialismo versus Prácticas Locales. La decolonización del discurso managerial desde la vida de la Escuela. Cuadernos de Administración, 32(58). https://doi.org/10.11144/javeriana.cao.32-58.mvpl

Sisto, Vicente, \& Zelaya, Victor (2014). La Etnografía de Dispositivos y el estudio de los instrumentos de rendición de cuentas como prácticas. Universitas Psychologica, 12(4), 1345-1354. https://doi.org/10.11144/javeriana.upsy12-4.edha

Strangleman, Tim (2005). Sociological Futures and the Sociology of Work. Labour Process. 10(4). https://doi.org/10.5153/sro.1198 


\section{VICENTE SISTO}

Dr. en Psicología Social por la Universitat Autònoma de Barcelona. Profesor Titular Pontificia Universidad Católica de Valparaíso, Investigador Principal Centro de Investigación para la Educación Inclusiva e Investigador Adjunto Núcleo Milenio Autoridad y Asimetrías de Poder.

vicente.sisto@pucv.cl

https: / / orcid.org/0000-0003-4510-4041

\section{CARLA FARDELLA}

Doctora en Psicología Social de la Universidad Autónoma de Barcelona. Investigadora de la Facultad de Educación y Ciencias Sociales, Universidad Andrés Bello. Su investigación se orienta al análisis de políticas públicas para la ciencia y al desarrollo de metodologías cualitativas para el estudio de diferentes áreas de la psicología social.

carla.fardella@unab.cl

https://orcid.org/0000-0001-8936-2435

\section{AGRADECIMIENTOS}

Este trabajo cuenta con el apoyo del Fondo Nacional para el Desarrollo de la Ciencia y la Tecnología de Chile (Fondecyt, proyectos 1180129 y 1191015), de la Subdirección de Centros e Investigación Asociativa (SCIA) de la Agencia Nacional de Investigación y Desarrollo (ANID), Centro CIE160009, del Programa Iniciativa Científica Milenio de ANID (NCS17_ 007), y del Programa de Investigación Asociativa (PIA) SOC180039.

\section{FORMATO DE CITACIÓN}

Sisto, Vicente \& Fardella, Carla (2021). Estudiar las transformaciones contemporáneas del trabajo desde una perspectiva psicosocial. Quaderns de Psicologia, 23(2), e1871. https://doi.org/10.5565/rev/qpsicologia. 1871 